\title{
The Distribution of Hypertension in the Philippine General Hospital after 4 Decades (A Comparative Study)
}

\author{
Deborah David-Ona, Dexter M. De Castro and Aida C. Baltazar
}

Section of Hypertension, Department of Medicine, College of Medicine and Philippine General Hospital, University of the Philippines Manila

\begin{abstract}
Objective. The prevalence of hypertension is $20 \%$ in the Philippines, and it increases year after year. It remains a risk factor for coronary heart disease, stroke, and heart and renal failure. The gravity of complications from hypertension also reflects the effectiveness of the awareness programs in the Philippines. The patient population of the Philippine General Hospital (PGH), being a tertiary referral center in the Philippines, has been represented by indigenous groups of Filipino people from the different provinces in the Philippines. In 1966, Dr. Baltazar conducted a study on the pattern of distribution of hypertension in PGH. It showed that essential hypertension was the leading cause of admission in PGH. This study aims to determine the prevalence and distribution of hypertensives admitted to PGH after four decades of improvement in the diagnosis and treatment of hypertension in the Philippines.
\end{abstract}

Methods. Chart review of all hypertensive patients admitted at the charity wards or intensive care units in PGH in 2005 was performed. The year 2005 was selected due to the limitation of the Medical Records Section in retrieving charts before that year. Data from the Department of Pediatrics was excluded due to the insignificant number of hypertensives seen by the Department.

Results. The information obtained from this study showed a decline in prevalence from $8.4 \%$ in 1966 to $4.1 \%$ in 2005 with a predominance of pregnancy-related hypertension in 1966 compared with primary hypertension in 2005.

Conclusion: This comparative study shows an expected decline in the prevalence of hypertension among admitted patients which can be attributed to heightened hypertension awareness, screening programs, and good quality of care.

Key Words: hypertension, distribution, tertiary hospital, Philippines

Corresponding author: Deborah David-Ona, MD

Section of Hypertension

Department of Medicine

Philippine General Hospital

University of the Philippines Manila

Taft Avenue, Ermita, Manila, 1000 Philippines

Telephone: +6325264372

Email: debbiedavidona@gmail.com

\section{Introduction}

Hypertension is a major public health problem not only in the Philippines but worldwide. The global prevalence of hypertension in 2000 is $26 \%$ and is projected to increase to $29 \%$ by the year $2025 .{ }^{1}$ In the Philippines, the prevalence of hypertension is $20 \%$, and it increases year after year. ${ }^{2,3}$ It remains a risk factor for coronary heart disease, stroke, and heart and renal failure. Although the mortality rate for stroke has been on the decline since the 1960s in developed countries in Asia, a rapid increase in stroke has been observed in the Philippines. ${ }^{4}$ Despite the alarming complications of hypertension, a significant percentage $(32 \%)$ of the Filipino hypertensives have uncontrolled hypertension. ${ }^{3}$ In addition, $16 \%$ of hypertensives are not aware of their disease. ${ }^{3}$ The majority of hypertensives already have target organ damage. ${ }^{5}$ Along with the substantial increase in morbidity and mortality from hypertension, the cost of health care in the management of the complications of hypertension is increasing. The gravity of the complications from hypertension also reflects the effectiveness of the awareness programs in the Philippines.

The patient population of the Philippine General Hospital (PGH), being a tertiary referral center in the Philippines, has been represented by indigenous groups of Filipino people from the different provinces in the Philippines. In 1966, Dr. Baltazar conducted a study on the pattern of distribution of hypertension in PGH. ${ }^{6}$ It showed that essential hypertension was the leading cause of admission in PGH. This study aims to determine the prevalence of hypertension and the distribution of hypertension among patients admitted to PGH after four decades of improvement in the diagnosis and treatment of hypertension in the Philippines.

\section{Objectives}

\section{Primary objectives}

1. To investigate the prevalence of hypertension in PGH in 2005 compared to data published in the 1966 study.

2. To determine the difference in the distribution of hypertension among patients admitted to PGH in 1966 and 2005. 


\section{Review of Related Literature}

Hypertension has been defined by JNC7 as systolic blood pressure greater or equal to $140 \mathrm{mmHg}$ or diastolic blood pressure greater than or equal to $90 \mathrm{mmHg}$. It is described as Stage 1 if the BP is $140-159 \mathrm{mmHg}$ systolic or 90-99 $\mathrm{mmHg}$ diastolic; and Stage 2 if BP is $\geq 160 \mathrm{mmHg}$ systolic or $\geq 100 \mathrm{mmHg}$ diastolic.

The known risk factors for hypertension are age, family history and body mass index. ${ }^{7}$ The parameters in the assessment and definition of target organ damage includes the heart (left ventricular hypertrophy, ischemic heart disease, congestive heart failure, arrhythmia, heart blocks, and myocardial infarction), kidney (proteinuria, renal insufficiency, and end-stage renal disease), brain (stroke, transient ischemic attack, reversible neurologic disease), eyes (retinopathy), and peripheral vascular system (claudication).

\section{Methods}

\section{Overall study design and plan-description}

This is a descriptive study on hypertensive patients admitted to the PGH charity service in 2005. Chart review of all hypertensive patients admitted to the charity wards or intensive care units in PGH in 2005 was performed. Diagnosis of hypertension was obtained by looking at the admission diagnosis, entry in the charts, as well as discharge diagnosis. The charts were then retrieved and reviewed and the number of hypertensives totalled to get the percentage of the total admissions, type of distribution and complications of the disease. Data from the retrieved charts was then tabulated to facilitate analysis.

The year 2005 was selected due to the limitation of the Medical Records Section in retrieving charts before 2005. This was also the year that a computerized database was used, allowing for easy retrieval of charts. The Department of Pediatrics was excluded due to insignificant number of hypertensives seen by the department.

\section{Selection of study population}

Inclusion Criteria

1. All charity patients diagnosed with hypertension admitted to PGH in the year 2005

2. All adult patients (age $\geq 18$ years old)

3. Patients with essential or secondary hypertension

\section{Exclusion Criteria}

1. Patients admitted to pay-patient floors

2. Non-hospitalized patients

3. Pediatric patients

\section{Analysis of Data}

From the masterlist in the database, there were a total of 27,316 admitted patients in the charity wards in 2005. From the list tallied in the database, we determined the number of hypertensive admissions for the year for each department (Tables 1-3) and compared it with the previous study of Dr. Baltazar in 1966. We then retrieved the charts of all hypertensive patients that satisfied our inclusion criteria. We were able to retrieve a total of 912 charts from the 1,114 patients that were listed in the database. From the 912 charts, data on the number of hypertensives per department, type of hypertension and their complications (Tables 4-5), was recorded and analyzed.

\section{Results and Discussion}

A total of 27,316 patients were admitted at PGH in the year 2005 compared to 18,628 patients in the year 1966 .

Table 1 shows a comparative summary of PGH admissions classified as hypertensive and non-hypertensive. Of the 27,316 patients in 2005 , only 1,114 patients $(4.1 \%)$ were hypertensive, compared to 1,558 (8.4\%) hypertensive patients out of the 18,628 admitted in 1966. However, of the 1,114 patients, we were able to retrieve only 912 charts. Data from these charts was recorded and analyzed accordingly.

Table 1. PGH admissions in 1966 and 2005

\begin{tabular}{lcccc}
\hline \multirow{2}{*}{ PGH admissions } & \multicolumn{2}{c}{1966} & \multicolumn{2}{c}{2005} \\
\cline { 2 - 5 } & Total & \% & Total & $\%$ \\
\hline Hypertensive & 1,558 & 8.40 & 1,114 & 4.10 \\
Normotensive & 17,070 & 91.60 & 26,202 & 95.90 \\
Total & 18,628 & 100.00 & 27,316 & 100.00 \\
\hline
\end{tabular}

Table 2 illustrates the total number of hypertensive patients in the five clinical departments in relation to the total number of admissions (including non-hypertensives). It should be noted that the Department of Medicine had the most number of hypertensive patients in both 1966 (29.55\%) and 2005 (9\%). In our study, the department with the second most number of hypertensive patients was the Department of Obstetrics and Gynecology (3.81\%), followed by Surgery $(0.58 \%)$. The Departments of Ophthalmology and Otorhinolaryngology had no hypertensive patients who were admitted to their wards, which could indicate that the hypertension diagnosis was not written in the charts as these might have been evaluated preoperatively and that the hypertension was controlled or that hypertension was not really a co-morbid condition in their patients. This was a stark contrast from the previous study in 1966 wherein the ENT Department ranked second and the Ophthalmology Department ranked fourth in the most number of hypertensive admissions.

Table 3 compares the distribution of hypertensives in the five clinical departments over the total number of hypertension patients that were admitted for the years 1966 and 2005. This table shows that in the year 2005 the Department of Medicine (52.5\%) ranked first as the Department with the most number of hypertensive patients followed by OB-Gyne (43.3\%), which ranked first in 1966, 
followed by Surgery (4.2\%). In 2005, there were no reported hypertensive patients in the Department of ENT and Ophthalmology.

Table 2. Distribution of hypertension in PGH per department admission for 1966 and 2005

\begin{tabular}{lcccccc}
\hline \multirow{2}{*}{$\begin{array}{c}\text { PGH } \\
\text { admissions }\end{array}$} & $\begin{array}{c}\text { Total \# of } \\
\text { Admitted } \\
\text { Patients }\end{array}$ & $\begin{array}{c}\text { \# of } \\
\text { hypertensives }\end{array}$ & \% & $\begin{array}{c}\text { Total \# of } \\
\text { Admitted } \\
\text { Patients }\end{array}$ & $\begin{array}{c}\text { \# of } \\
\text { hypertensives }\end{array}$ & \% \\
\hline ENT & 279 & 16 & 5.70 & 1,037 & 0 & 0.00 \\
Ophtha & 342 & 52 & 15.20 & 1,475 & 0 & 0.00 \\
Medicine & 2,377 & 460 & 19.30 & 5,321 & 479 & 9.00 \\
Surgery & 3,478 & 116 & 3.30 & 6,752 & 38 & 0.58 \\
OB-Gyne & 12,152 & 914 & 7.50 & 10,350 & 395 & 3.81 \\
Total & 18,628 & 1,558 & 8.36 & 24,935 & 912 & 3.65 \\
\hline
\end{tabular}

Table 3. Distribution of hypertension in PGH compared to the total number of hypertensive admissions in the year 1966 and 2005

\begin{tabular}{lcccc}
\hline \multirow{2}{*}{$\begin{array}{c}\text { PGH } \\
\text { admissions }\end{array}$} & \multicolumn{2}{c}{$\mathbf{1 9 6 6}$} & \multicolumn{2}{c}{$\mathbf{2 0 0 5}$} \\
\cline { 2 - 5 } & \# hypertensives & $\mathbf{\%}$ & \# hypertensives & $\mathbf{\%}$ \\
\hline ENT & 16 & 1.00 & 0 & 0.00 \\
Ophtha & 52 & 3.30 & 0 & 0.00 \\
Medicine & 460 & 29.50 & 479 & 52.50 \\
Surgery & 116 & 7.40 & 38 & 4.20 \\
OB-Gyne & 914 & 58.70 & 395 & 43.30 \\
Total & 1,558 & 100.00 & 912 & 100.00 \\
\hline
\end{tabular}

Table 4 illustrates the breakdown of the different types of hypertension according to etiology. In 2005, 909 out of the 912 patients were classified according to the types of hypertension; 3 charts were not classified as there was inadequate work-up due to a very short admission or the patients were admitted for a coexisting disease. In 1966, only 1,297 charts were retrieved out of the 1,558 charts. Either some charts were listed as borrowed but not returned by doctors, or when the charts were reviewed there was inadequate work-up due to very short admission times or the patients were confined for a coexisting disease and not necessarily hypertension. As expected, the most common etiology for hypertension in the year 2005 was primary or essential hypertension $(65.01 \%)$. This is consistent with the findings because most of the hypertensive patients were admitted to the medical wards. Second, third, and fourth in rank with regards etiology were types of hypertension in pregnancy, mainly pre-eclampsia, eclampsia (16.61\%), gestational hypertension (7.04\%) and pre-eclampsia superimposed on primary hypertension (5.94\%). It is worth noting that the number of patients with hypertension in pregnancy decreased after four decades whereas in 1966 $(60.33 \%)$ it was the number one etiology of admitted hypertensive patients. This can be due to the increased awareness of these patients and improved prenatal care. Also in 2005, there was an increased number of patients with chronic kidney disease: $5.28 \%$ compared to $0.46 \%$ in 1966 .
There was also one reported case of Cushing's syndrome as the cause of the hypertension in 2005. This may be explained by improved screening, work-up, and management of hypertensive patients.

Table 4. Distribution of different types of hypertension in PGH for 1966 and 2005

\begin{tabular}{llcccc}
\hline \multirow{2}{*}{ Rank } & Types of hypertension & \multicolumn{2}{c}{1966} & \multicolumn{3}{c}{$\mathbf{2 0 0 5}$} \\
\cline { 3 - 6 } & & $\begin{array}{c}\text { Number of } \\
\text { hypertensives }\end{array}$ & \% & $\begin{array}{c}\text { Number of } \\
\text { hypertensives }\end{array}$ & \% \\
\hline 1. & Probable primary & 443 & 34.50 & 591 & 65.01 \\
2. & Pre-eclampsia/ eclampsia & 785 & 60.33 & 151 & 16.61 \\
3. & Pre-eclampsia/ eclampsia & 19 & 1.46 & 54 & 5.94 \\
& superimposed on primary & & & & \\
4. & Gestational Hypertension & 0 & 0.00 & 64 & 7.04 \\
5. & CKD & 6 & 0.46 & 48 & 5.28 \\
6. & Aortic Insufficiency & 6 & 0.46 & 0 & 0.00 \\
7. & Chronic glomerulonephritis & 16 & 1.22 & 0 & 0.00 \\
8. & Chronic pyelonephritis & 12 & 0.92 & 0 & 0.00 \\
9. & Cushing's syndrome & 2 & 0.15 & 1 & 0.11 \\
10. & Renovascular HPN & 5 & 0.38 & 0 & 0.00 \\
11. & SLE & 1 & 0.07 & 0 & 0.00 \\
12. & Polycystic kidneys & 1 & 0.07 & 0 & 0.00 \\
13. & Pheochromocytoma & 1 & 0.07 & 0 & 0.00 \\
14. & Atherosclerosis & 0 & 0.00 & 0 & 0.00 \\
15. & Acute Glomerulonephritis & 0 & 0.00 & 0 & 0.00 \\
& Total & 1,297 & 100.00 & 909 & 99.99 \\
\hline
\end{tabular}

This study also looked at the complications associated with hypertension and Table 5 shows that the most common complication in the patients admitted in 2005 was ischemic heart disease $(6.3 \%)$, followed by chronic kidney disease $(5.1 \%)$, then hypertensive retinopathy $(1.9 \%)$ and myocardial infarction $(0.18 \%)$. Although there was no data regarding complications in the study in 1966, we include this information because it tells us that there is a need to control the blood pressure early on in the disease to prevent the more fatal complications.

Table 5. Complications of Hypertension in 2005 (no data for 1966)

\begin{tabular}{lcc}
\hline \multicolumn{1}{c}{ Complications } & No of Hypertensives & \% \\
\hline 1. Ischemic Heart Disease & 70 & 7.70 \\
2. Myocardial Infarction & 2 & 0.22 \\
3. Chronic Kidney Disease & 57 & 6.30 \\
4. Aortic Dissection & 0 & 0.00 \\
5. Hypertensive Retinopathy & 21 & 2.30 \\
6. Stroke & 106 & 11.60 \\
\hline
\end{tabular}

The information obtained from this study showed that there was a decline in the prevalence of hypertension from $8.4 \%$ in 1966 to $4.1 \%$ in $2005,50 \%$ less than four decades ago. This could be explained by the remarkable progress in the last few decades in terms of detection facilities, diagnostic methods and treatment (both non-pharmacologic and pharmacologic) of hypertension. There was also a predominance of pregnancy-related hypertension in 1966, whereas in 2005 primary hypertension was seen, which can 
be explained by better prenatal care. Moreover, this is a reflection that probably more patients experienced complications and therefore needed to be admitted for hypertension.

This comparative study shows an expected decline in the prevalence of hypertension among admitted patients which can be attributed to heightened hypertension awareness, screening programs, and good quality of care in the outpatient setting.

\section{Acknowledgements}

The authors would like to acknowledge the following people who have contributed to this paper: Dr. Patricia Salvador, Dr. Marie Elaine Velasquez, Dr. Mary Gay Buliyat, Dr. Marissa Lim, Dr. Elajy Comeily-Birjandi, Dr. Omar Mejia, Dr. Aveline Sue Anne Lim, Dr. Lowe Chiong, Dr. Jerome Ramos, Dr. Geraldine Racaza, and Ms. Angel de Leon.

\section{References}

1. Kearney PM, Whelton M, Reynolds K, Whelton PK, He J. Global burden of hypertension: analysis of worldwide data. Lancet. 2005; 365(9455):217-23.

2. Dans A, Morales D, Velandria F, et al. National Nutrition and Health Survey (NNHeS): Atherosclerosis-related disease and risk factors. Philipp J Intern Med. 2005; 43(3):103-15.

3. Sison, et al. PRESYON2, Summary of Research Findings [Online]. 2005 [cited 2011 July]. Available from http://www.psh.org.ph/v2/PRESYON 2- PHA 07.pps

4. Sison JA, Atabug J. Philippine Hypertension and Target Organ Survey (Phyton). Japanese Circulation Journal. 1996; 60suppl1:545.

5. International Medical Foundation of Japan. Southeast Asian Medical Information Center Health Statistics. Japan: SEAMIC; 1996.

6. Baltazar A, et al. The Distribution of hypertension in the Philippine General Hospital. Acta Medica Philippina. 1976; 13suppl2(2).

7. Reyes-Gibby CC, Aday LA. Prevalence of and risk factors for hypertension in a rural area of the Philippines. J Community Health. 2000; 25(5):389-99.

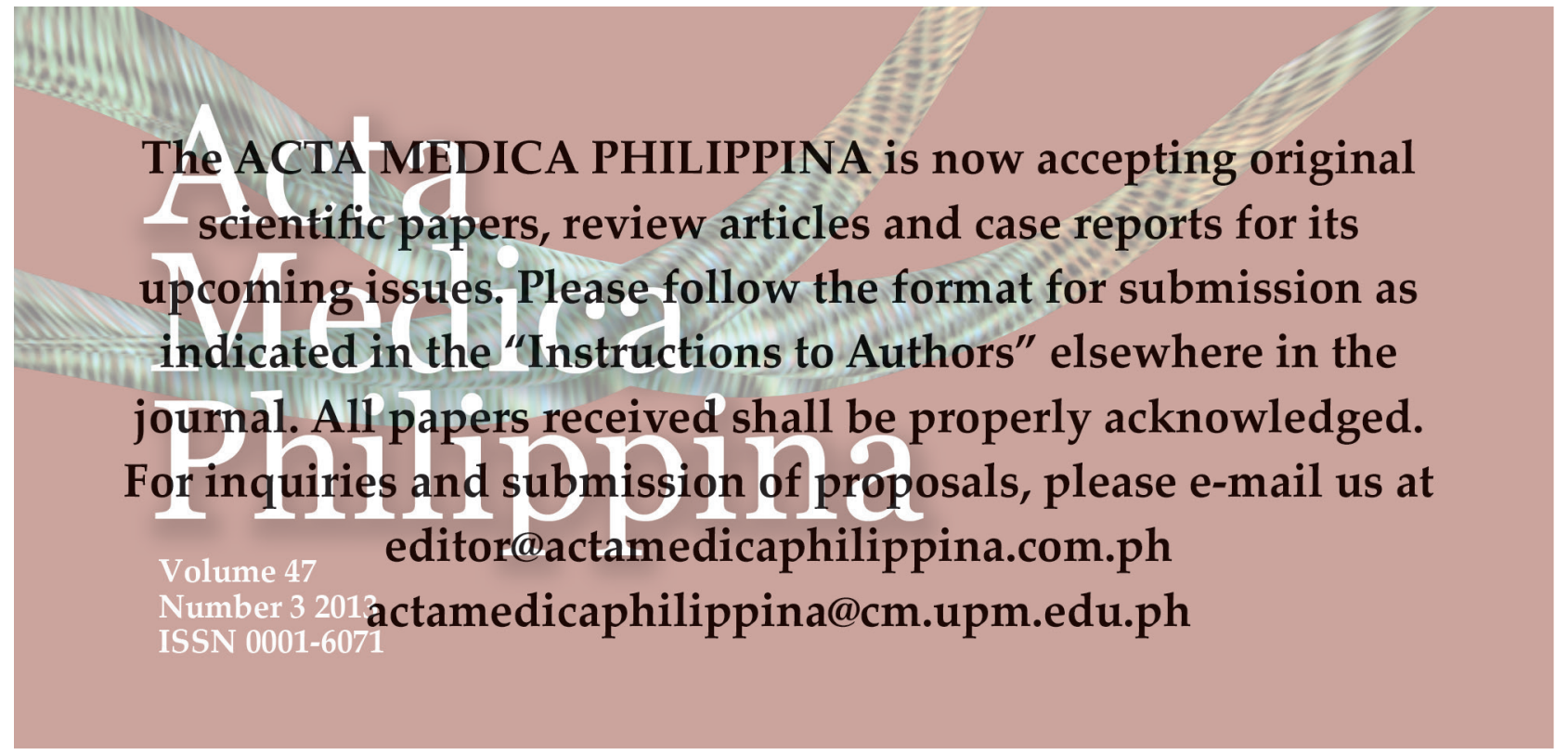

